\title{
Using Spatial Concepts to Integrate Data and Information from Various Sources for a Knowledge-based Assessment of Impervious Surfaces
}

\author{
Thomas Strasserl and Dirk Tiede ${ }^{1}$ \\ 'University of Salzburg
}

\begin{abstract}
In this study, we present a concept for the assessment of impervious surfaces integrating VHR satellite data and a-priori information from additional datasets. Spatial concepts like neighbourhood and region, distance, spatial dependence or spatial variability are adapted in a knowledge-based approach using an object-based image analysis model to accumulate evidence from different sources. We look at constraints for timely and comprehensive VHR optical data acquisition that covers larger areas with adequate image characteristics (sensor family, seasonality, sensor viewing angles and sun inclination). For a study area covering the municipality of Hallein (Austria), we discuss preliminary results with a focus on real-world object characterization (including surface material, spectral reflectivity, object size and shape) and on building a knowledge-base for the classification of real-world objects. We also assess image characteristics and effects on image analysis. The knowledge about real-world object characteristics and image object statistics will be used to develop an integrated approach that aims for transferability to larger areas.
\end{abstract}

\section{Keywords:}

imperviousness, VHR Pléiades imagery, OBIA, rule-based approach, data integration

\section{Introduction}

Knowing the spatial distribution and the annual increase of impervious surfaces (i.e. soilsealing) is of high community interest and is used as an important indicator for spatial management and planning actions. In particular, soil-sealing causes the loss of the biological functions of soils and soil fertility, the loss of ecological functions and biodiversity, the increase of natural disasters (e.g. flooding), the reduction of quality of life, and the missing of climatechange goals (e.g. due to heat effects). The Environment Agency Austria assesses annually the total area of artificial impervious surfaces, using the available digital cadastral information, the result being a soil-sealing rate of approximately 12.0 ha/day for the period 2017-2019 (Umweltbundesamt, 2020). However, due to delays that are the result of the process of cadastral data assessment (several years; sporadic update of data), the results do not necessarily reflect the current situation of soil-sealing in Austria. In this context, we use the term 
'imperviousness' or 'impervious surface area' synonymously for human-driven (artificially) soil-sealed areas; natural bedrock and bedrock material (e.g. rock debris) are not considered 'impervious surfaces'.

Optical satellite data with very high spatial resolution (VHR) and state-of-the-art data analysing methodologies provide standardized, reproducible, transparent and timely analysis products with a mapping scale $<1: 5000$. Thus, VHR analytic products fulfil the technical requirements needed for fine-scale spatial management and planning actions. Impervious surface areas can be derived from VHR imagery by the specific spectral reflectance of the surface materials used (Weng, 2012), which are usually mineral, metallic or of hydrocarbon origin (Heiden et al., 2007; Kotthaus et al., 2014). However, analysing imperviousness in urban and urban-rural environments based on VHR satellite imagery is challenging, as the variety of real-world objects results in complex image content with high spectral heterogeneity (Weng, 2012; Myint et al., 2011; Hamedianfar et al., 2014). In urban areas, impervious surfaces comprise mainly man-made constructions like buildings (with different sorts of roofing materials), roads, parking areas, pavements, squares, sports fields, permanent swimming pools and others, which are fully or partially impervious (Hamedianfar et al., 2014; Heiden et al., 2007). Real-world objects can be characterized by a sensor/image model and a scene model, a simplification of the real world, which describe objects 'as the analyst would like to extract them from images in terms relevant to image processing' (Blaschke et al., 2014; Strahler et al., 1986). Thus, objects can be interpreted from images, e.g. by their size, shape, texture and context. Using other data sources (e.g. LiDAR or multitemporal images), the set of describing attributes is expanded with information on object height, topographic information and surface roughness, as well as with temporal characteristics (seasonal variation, change, or stable conditions). By summarizing these attributes of real-world objects in a knowledge-base and formulating specific rules, the information can be converted into a consistent hierarchical (semantic) model of remote sensing-based land-cover and land-use types (Andrés et al., 2017; Arvor et al., 2019). However, depending on the spatial and spectral resolution of the satellite sensors used, the granularity of the derived information varies.

In what follows, a conceptual object- and knowledge-based classification framework using earth observation (EO) data is presented. The classification aims in general terms to be of use for annual monitoring of artificial impervious surfaces, from regional to national scale (map scale of analysis products $<1: 5000$ ). Preliminary analysis results for the study area of Hallein (Austria) are also discussed. The methodological framework includes: 1) considerations with respect to data availability (revisit period, required sensor parameters for full area coverage) and resulting data quality; 2) transparency, reproducibility and transferability of the methodology; 3) improvement of results by a comprehensive integration of a priori knowledge in the form of ancillary data and the use of spatial concepts in the information-extraction process. 


\section{Objectives and Methodological Framework}

Spatial management and planning institutions need comprehensible up-to-date spatial information of very high resolution and quality (map scale $<1: 5000$ ) for monitoring and decision support. In Austria, currently, aerial orthographic imagery with a ground sample distance of $<25 \mathrm{~cm}$ is used as base data to derive adequate information by expert-based visual interpretation and manual delineation. In general, this approach is both labour and time intensive, and thus expensive. Although orthophotos are available in Austria every three years (consisting of spectral bands red, green and blue (RGB); near infrared band (NIR) is optional), because of the missing spectral calibration of data and the absence of yearly repetition these data are inappropriate for cost-effective large-scale data analysing methodologies that use a high degree of automation. On the other hand, large-scale analysis products of impervious surface areas, like the European-wide high-resolution layer of imperviousness ${ }^{1}$ (HRL Imperviousness, $20 \mathrm{~m}$ pixel resolution), offer insufficient spatial detail and are not sufficiently up-to-date (3-year repetition interval, delayed distribution) to meet the spatial management requirements of local planning authorities.

Recent VHR satellite imagery fulfils the requirements of spatial and spectral resolution (at least $<1 \mathrm{~m}$ panchromatic, RGB and NIR bands, top-of-atmosphere (TOA) calibrated), as well as ready data acquisition over large areas in a specific timeframe and at yearly intervals (Banko et al., 2014). However, to achieve complete VHR-imagery coverage using the same sensor family for a larger area in a certain timeframe, constraints in image quality (primarily sensor-viewing, shadow and temporal effects) must be considered. Knowledge-based or rule-based approaches can foster the transparency of data-analysing methodologies, and in the best case their reproducibility and transferability using other data of similar characteristics. Object-based approaches minimize the salt-and-pepper effect that could emerge from using pixel-based approaches (Blaschke and Strobl, 2001) and allow a complete attribution of real-world objectfeatures and their relations (Lang, 2008; Tiede et al., 2010). Data integration of available apriori information increases cost-efficiency and enhances image classification stability and validity through evidence accumulation (Matsuyama and Hwang, 1990).

In general, impervious surface materials differ spectrally in VHR imagery from vegetation (high reflectance in the NIR band), water or shadow (low reflectance in the NIR band), and snow (high reflectance in RGB and NIR bands). Additional 2.5D information (in our case, based on LiDAR data) on object height and object-height variation (i.e. homogeneity or 'roughness') is valuable to distinguish real-world objects of similar spectral reflectivity, but differing in height (e.g. roads vs. buildings, or grassland - shrubs - trees). Even if the LiDAR data is not up to date, it may help in defining the initial status quo as an additional source of evidence - i.e. the state of affairs pertaining when further monitoring is initialized using VHR optical data only. Ancillary data may be useful for identifying imperviousness that has already been assessed, as well as for distinguishing the likelihood of impervious surface areas based on spatial concepts (e.g. buildings occur primarily next to roads). Still, additional data must be evaluated regarding its availability, precision, areal coverage, date and completeness.

${ }^{1}$ Copernicus land monitoring service - Pan-European High Resolution Layers (2006-2015):

https://land.copernicus.eu/pan-european/high-resolution-layers 
Developing an appropriate data-analysis approach requires various factors to be taken into consideration. Hence, we propose the following methodological framework for a knowledgeand object-based image analysis (OBIA) approach to identify artificial impervious surfaces from VHR optical data, and to monitor their development over time in the context of soilsealing:

- General considerations

1. The methodological design is modular, extendable and adaptable (i.e. has the potential to be developed further, e.g. integration of optional thematic information or of future remote-sensing data, as well as of multi-temporal analysis of big-data analysis solutions)

2. Reducing free parameters in the image classification as much as possible and enriching rule-based classification using valid spatial concepts / spatial relations to increase transparency, reproducibility and transferability of the methodology. Doing this also takes into account the main issues (principally viewing geometry and image registration) for further annual change detection monitoring by integrating concepts of object-based change detection (Chen et al., 2012)

3. Extracting impervious surface areas primarily from VHR optical data (the data actuality is of utmost importance), but enriching the classification results with additional information in a rule-based classification (e.g. correction of object shadow effects, or building displacement resulting from sensor-viewing effects).

- Considerations for defining the main pillars of the technical implementation

4. Top-of-atmosphere calibrated VHR satellite imagery, ideally from just one sensor family, is able to cover the area of interest yearly within a specific timeframe (e.g. Pléiades, WorldView-2/3, SuperView-1 etc.). This is the most important data source; hence, other data sources (often not the most recent ones) provide further evidence but are weighted less compared to the up-to-date VHR data.

5. Building a knowledge base (Andrés et al., 2017) that contains a qualitative description of real-world objects with certain attributes and values, a sensor-specific statistical characterization of image objects, and a formulation of rules to represent real-world objects in images. For the statistical characterization, ancillary information on buildings, roads, vegetation, water etc. help to reduce the subjectivity in the sampling procedure. Information on image objects is contained in an object feature library (Strasser et al., 2014), which consists of spectral statistics, and structural, textural and shape-related information on different spatial and spectral scales.

6. Using image segmentation algorithms based on knowing the pros and cons (Hossain and Chen, 2019); increasing the transferability of the methodology by using strategies of over-segmentation (over-segmented image objects can still be merged based on additional knowledge; Drăguț et al., 2014), which makes the subsequent enhancement of object delineation easier by integrating expert-knowledge and ancillary information.

7. Developing expert rules and stable classes for data classification and to mitigate data limitations (primarily spatial displacement of objects due to sensor viewing angles, shadow and temporal effects), using the information from the knowledge base. 
8. Indication of classification probability: integrating expert knowledge on contextual coherence increases the plausibility, stability and transferability of the assessment (e.g. buildings are more likely next to a road; natural rock is more likely than other forms of impervious surface close to streams or rivers).

\section{Study area and Data}

The municipality of Hallein (47.683 N, 13.090 E) is located in the federal state of Salzburg (Austria). Hallein covers $26.98 \mathrm{~km}^{2}$ and is characterized by urban structures (roads and buildings, industrial areas), as well as urban-rural structures (mix of small and large buildings, roads, grassland, agricultural land, forest). In this area, around 9,600 buildings were identified from ancillary building data; $75 \%$ of buildings are less than $10 \mathrm{~m}$ high and $95 \%$ are less than $16.5 \mathrm{~m}$. Altitude ranges from 420 to $1,368 \mathrm{~m}$, resulting in an altitudinal vegetation zonation from sub-montane to high-montane. Figure 1 shows seasonal characteristics in Hallein indicated by the phenological season (vegetation period, snow-free period and period of low precipitation). Additionally, sun inclination and cloud-free periods are used to detect optimal and sub-optimal satellite-image acquisition periods for multi-purpose usage (optimal: beginning of June to mid-August; sub-optimal: mid-April to end of May / mid-August to end of September).

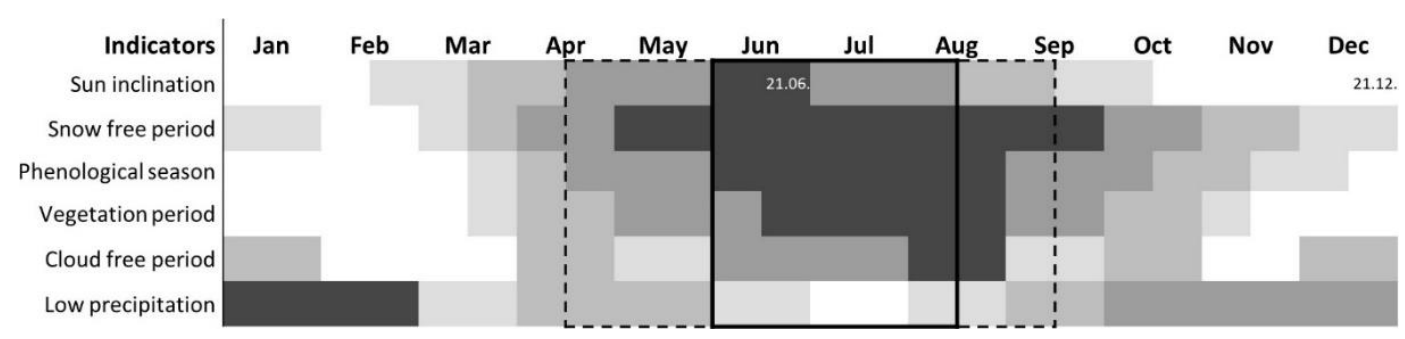

Figure 1: Optimal (black frame) and sub-optimal (dashed frame) image-acquisition periods for multipurpose usage in the area of Hallein, derived from six different indicators. Indicators categorized from dark (favourable) to light (less favourable): sun inclination (at $47^{\circ}$ latitude, highest inclination on 21.06 and lowest on 21.12); snow-free period (expert interpretation by webcam analysis); phenological season (in-situ observations ${ }^{2}$ of vegetation); vegetation period (daily temperature $\geq 10^{\circ}$ for Salzburg ZAMG ${ }^{3}$; c cloud-free period (using EO-Compass ${ }^{4}$ meta-data analysis of Sentinel-2 time series); low precipitation (daily precipitation measurement at Salzburg airport).

VHR Pléiades satellite imagery (RGB and NIR $2 \mathrm{~m}$ pixel resolution ${ }^{5}$, and $0.5 \mathrm{~m}$ panchromatic, 11-bit) was tasked within the optimal image acquisition period (see Figure 1). The imagery was

\footnotetext{
${ }^{2}$ ZAMG - Yearly phenological observations: https://www.zamg.ac.at/cms/de/klima/klimaaktuell/phaenospiegel/jahr

${ }^{3}$ ZAMG - Daily temperature and precipitation observations: https://www.zamg.ac.at/cms/de/klima/klimauebersichten/jahrbuch ${ }^{4}$ EO-Compass - Your map of the Sentinel-2 archive: http://eo-compass.zgis.at/ ${ }^{5}$ Spatial resolution provided by Airbus Defence and Space resampled from original spatial resolution $2.8 \mathrm{~m}$ (multi-spectral) and $0.7 \mathrm{~m}$ (panchromatic) respectively.
} 
acquired on 26.07 .2019 (sun elevation $59.4^{\circ}$, sun azimuth $150.9^{\circ}$ ) with a mean sensor inclination of $12.7^{\circ}$ and a mean viewing angle of $c a .20^{\circ}$. The image covers an area of $\sim 756 \mathrm{~km}^{2}$. Due to the viewing angle of the sensor, real-world objects are spatially displaced in the image to the southwest by a distance relating to their height. Thus, real-world objects less than $10 \mathrm{~m}$ high show an approximated maximum spatial displacement of $2.25 \mathrm{~m}$ in flat areas (other examples: $16.5 \mathrm{~m}$ high $\rightarrow 3.71 \mathrm{~m} ; 20 \mathrm{~m} \rightarrow 4.51 \mathrm{~m} ; 30 \mathrm{~m} \rightarrow 6.76 \mathrm{~m}$ ). High objects shadow to the north-north-west. Accordingly, the shadow of a $10 \mathrm{~m}$ high object in flat terrain is around $6 \mathrm{~m}$; objects of $15 \mathrm{~m}$ have shadows of $9 \mathrm{~m} ; 20 \mathrm{~m}$ high objects have shadows of ca. $12 \mathrm{~m}$. The Pléiades data was converted into TOA reflectance values and orthorectified using the rational polynomial coefficient (RPC) model as well as a LiDAR-Raster digital terrain model with $5 \mathrm{~m}$ spatial resolution (covering the federal state of Salzburg). Coregistration of images was conducted to the latest orthophotos (2017) using 44 ground control points (GCP); image pixel registration was in the coordinate system UTM33N. The coregistered multispectral and panchromatic images were combined to create a pansharpened image using the GramSchmidt methodology with specific weightings for the multispectral bands used (R / G / B / $\mathrm{NIR}=0.9 / 0.75 / 0.5 / 0.5$ respectively) .

Several datasets were tested for optional data integration, such as the latest (2016) LiDAR point cloud (point density 4-8 pts / $\mathrm{m}^{2}$, including a point cloud classification) and the derived digital elevation models (spatial resolution of 0.5 and $1 \mathrm{~m}$ pixel size), as were various thematic datasets (including data for buildings, roads, forests and water bodies; EU-defined IACS data for agriculture; biotope-type mapping).

\section{$4 \quad$ Initial steps and preliminary results}

\subsection{Building a knowledge base using samples and expert-based information}

Generally speaking, artificial impervious surfaces are constructions of different materials such as minerals (concrete, fibre cement, slate, roofing tiles, rock in the form of cobblestones, paving stones and loose chippings), metals (aluminium, zinc, copper, lead), or organic compounds (asphalt, asphalt concrete, tar paper, polyvinyl chloride, polyethylene, polyisocyanate etc.) (Heiden et al., 2007). In the near infrared spectral range, these materials differ mainly from water (absorbance) and vegetation (high reflectance); the reflectance in the near infrared spectral range is similar to the reflectance in the red spectral range, with some exceptions (e.g. plastic material). Other spectral characteristics can be attributed by colour in the visible spectral region. Additional object characteristics (size, shape etc.) are listed with descriptions and examples in Table 1. 


\section{Strasser et al}

Table 1: Real-world object attributes, additional descriptions and examples

\begin{tabular}{|c|c|c|}
\hline $\begin{array}{l}\text { Object } \\
\text { attributes }\end{array}$ & Additional description & $\begin{array}{l}\text { Examples, including land-cover or land- } \\
\text { use classes }\end{array}$ \\
\hline Size & $\begin{array}{l}\text { valuable to } \\
\text { characterize artificial } \\
\text { objects of certain size } \\
\text { and common dimensions }\end{array}$ & $\begin{array}{l}\text { cars / trucks (width }<2.6 \mathrm{~m} \text {; length } \\
<6 \mathrm{~m} \text { (cars) / < 18.75 m (trucks)); } \\
\text { small round swimming pools }\left(<36 \mathrm{~m}^{2} \text {, }\right. \\
\text { diameter }<7 \mathrm{~m} \text { ) }\end{array}$ \\
\hline Shape & specific shape or ratio & $\begin{array}{l}\text { rivers or roads (high ratio of length } \\
\text { to width) }\end{array}$ \\
\hline Texture & $\begin{array}{l}\text { high or low variance in } \\
\text { values }\end{array}$ & $\begin{array}{l}\text { grassland with low variance in values } \\
\text { vs. forest (high variance) }\end{array}$ \\
\hline $\begin{array}{l}\text { Neighbourhood / } \\
\text { distance }\end{array}$ & logical context & $\begin{array}{l}\text { cars on roads or parking lots; small } \\
\text { round swimming pool is close to a } \\
\text { house, distance to roads } \\
\text { (accessibility) }\end{array}$ \\
\hline Height & $\begin{array}{l}\text { difference in object } \\
\text { height }\end{array}$ & $\begin{array}{l}\text { roads vs. buildings; grassland }(<2 \mathrm{~m}) \\
\text { vs. shrubs }(2-5 \mathrm{~m}) \text { vs. trees }(>5 \mathrm{~m})\end{array}$ \\
\hline $\begin{array}{l}\text { Topographic } \\
\text { roughness (DTM) }\end{array}$ & $\begin{array}{l}\text { high or low variance in } \\
\text { values of digital } \\
\text { terrain models }\end{array}$ & $\begin{array}{l}\text { standing water bodies (flat), rock } \\
\text { debris (rough) vs. bedrock (less rough) }\end{array}$ \\
\hline $\begin{array}{l}\text { Surface } \\
\text { roughness (DSM } \\
\text { / nDSM) }\end{array}$ & $\begin{array}{l}\text { high or low variance in } \\
\text { values of (normalized) } \\
\text { digital surface models }\end{array}$ & $\begin{array}{l}\text { grassland with low variance in values } \\
\text { vs. forest (high variance); }\end{array}$ \\
\hline $\begin{array}{l}\text { Temporal } \\
\text { characteristics }\end{array}$ & $\begin{array}{l}\text { seasonal change or } \\
\text { stable characteristics } \\
\text { (change due to snow } \\
\text { excluded) }\end{array}$ & $\begin{array}{l}\text { roads (less change in spectral } \\
\text { reflectivity) vs. meadows (vegetation } \\
\text { growth stages - cropping event etc.) }\end{array}$ \\
\hline
\end{tabular}

Spectral characteristics of real-world objects were derived, pixel-based, from RGB and NIR Pléiades image bands using ancillary datasets and eCognition 9.5 (Trimble Geospatial) (see Figure 2). Using existing spatially-explicit data reduces the subjectivity of expert-driven sampling strategies and increases transparency and cost-effectiveness. The spectral information we extracted includes the band intensities and remote sensing-based indicators NDVI, NDWI, NDSI ${ }^{6}$. Statistics for minimum and maximum values, as well as data distribution between different quantiles, were calculated per class or specific category and visualized. The following ancillary data were used:

- Roads and parking areas: specific categories for road types (e.g. motorways, major roads to forest roads) were selected and extracted from the Austria-wide polyline GIP data ('Graphenintegrations-Plattform', a standardized dataset used by public administration; polyline = road centre); extraction was done by pixelating the polylines. Roads with more than one lane show less tree-canopy coverage than e.g. forest roads, which needs to be taken into account for optical image classification.

\footnotetext{
${ }^{6}$ NDVI (Normalized Difference Vegetation Index) = (NIR-R)/(NIR+R); NDWI (Normalized Difference Water Index $)=(G-N I R) /(G+N I R) ;$ NDSI (Normalized Difference Soil Index $)=(R-B) /(R+B)$.
} 
- Rooftops: a building dataset (polygon) was provided by the federal state administration of Salzburg. Simulating the spatial displacement of buildings in the image, a rule-based algorithm for growing and shrinking built objects was implemented using the building dataset and a LiDAR-Raster nDSM $(1 \mathrm{~m}$ spatial resolution). For areas where buildings post-date the LiDAR acquisition and/or the building dataset, the VHR information is essential.

- Forest: 60 randomly distributed circular sample areas with a diameter of $20 \mathrm{~m}$ (> 75.000 pixel) were selected within a forest dataset (map scale 1:10.000, provided by the federal state administration of Salzburg) and visually inspected for coverage by deciduous or coniferous trees.

- Meadows and agricultural land: EU IACS polygon data from 2019 (Integrated Administraion and Control System, European-wide) was used to extract spectral information from the middle of agricultural fields within a circular sample area of 20 $\mathrm{m}$ diameter. Samples exceeding the extent of the agricultural field were not considered. 211 grassland and 27 agricultural sample areas were analysed.

The sampling strategy using validated data of GIP, buildings and EU IACS is reproducible and transferable to approaches using similar characteristics (in terms of available data, spatial and temporal resolution, aim of analysis, geographic area etc.).
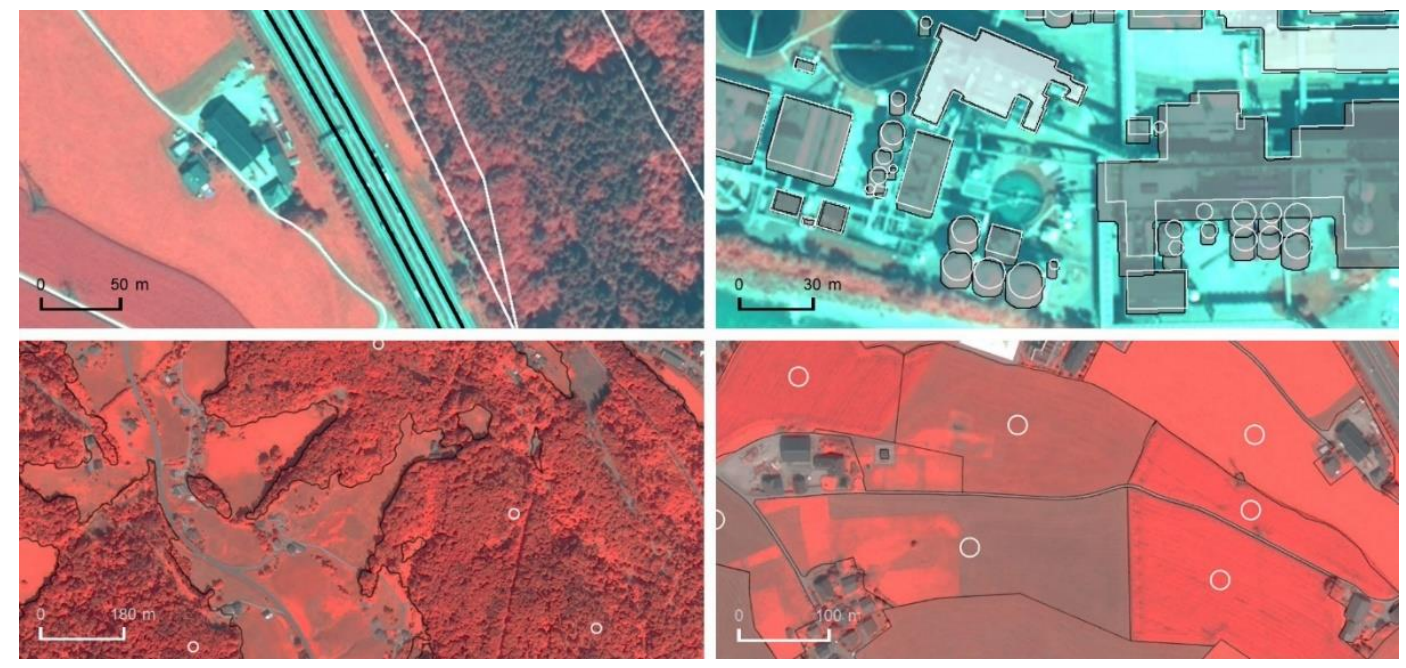

Figure 2: Sampling image pixel information using ancillary data. Upper left: motonway (black lines), roads of smaller order (white lines) including forest roads and tracks (partly covered by trees). Upper right: building data (white outlines) and modelled correction of the spatial displacement caused by the sensor view (black outlines); light-coloured buildings without correction vs. grey-coloured buildings. Lower left: randomly distributed sample circles (diameter $20 \mathrm{~m}$; white circles) within forest areas (black lines; map scale 1:10.000). Lower right: sample circles for grass and agricultural land (diameter $20 \mathrm{~m}$; white circles) in the centre of EU IACS fields (Integrated Administration and Control System; year 2019; black lines). 


\subsection{Image segmentation}

The well-known multi-resolution segmentation algorithm (Baatz and Schäpe, 2000) was used for building initial image segments based on Pléiades RGB and NIR bands. For the adjustment of the three variables - scale parameter (which controls the heterogeneity of pixel values forming an object), shape and compactness - the algorithm was adapted to a fully-automated iterative approach (expert-based definition of start- and end-point and increments, automated calculation of image objects, iteratively increasing parameters, and export to shape datasets). Selection of the best-fitting image objects for imperviousness assessment was based on an expert evaluation. Results derived using a scale parameter of around 120 and high values of shape and compactness were found to fit best for our approach (over-segmentation, including small real-world objects like swimming pools, delineation of real-world objects). Since the whole approach is designed for use with Pléiades data (to ease up-scaling), the selected parameters should be transferable to other areas of similar characteristics. Preliminary results of image segmentation are shown in Figure 3. Distinguishing small round swimming pools from surrounding elements is challenging, since swimming pools show similar reflectance values in the NIR spectral range to mineral or metallic material. This is because of the low absorbance of NIR light by shallow water. Optionally, a hierarchical segmentation might be implemented to overcome challenges in deriving real-world objects of different sizes (Drăguț et al., 2014) - for example by covering small real-world objects with segments on a lower scale, and larger objects on a higher scale. However, image segmentation and in particular the evaluation of image segmentation results are still biased to some degree, depending on the analyst.

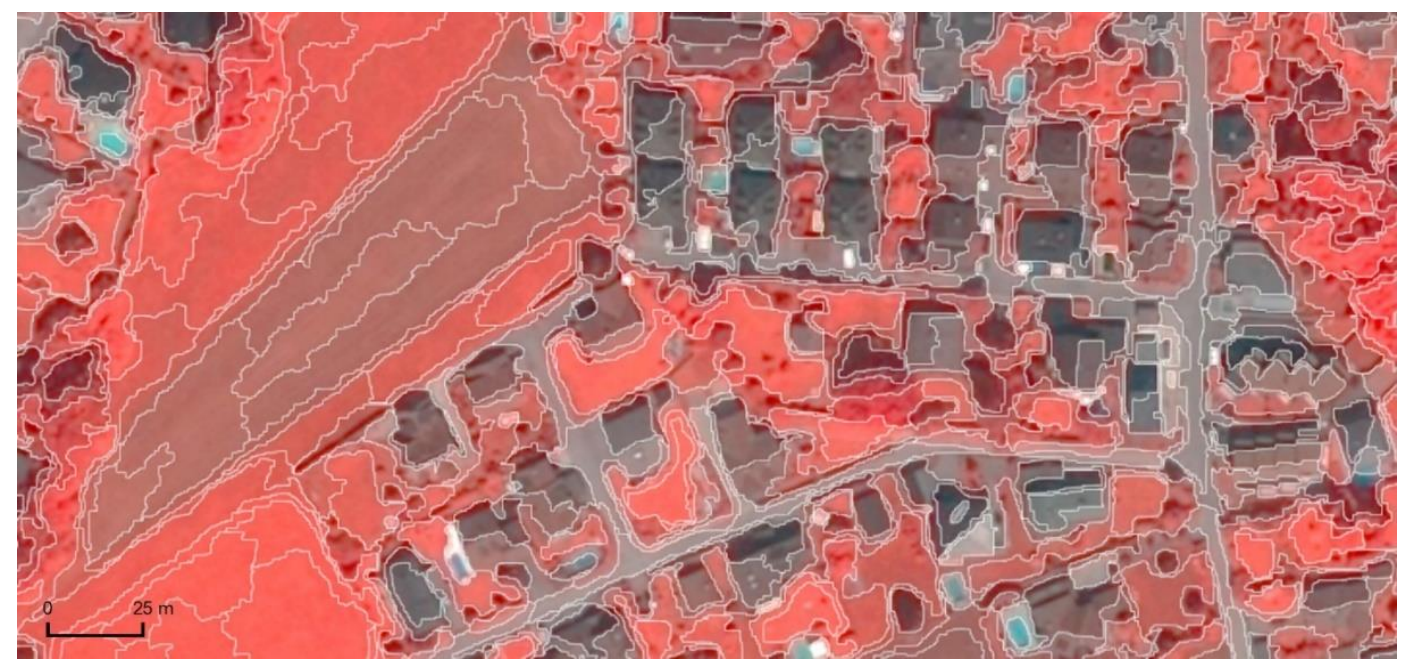

Figure 3: Expert-evaluated results of automated iterative multi-resolution segmentation. Image segments (white lines; scale parameter $=120$, shape $=0.6$, compactness $=0.9$; bands: $R G B$ and NIR) revealing over-segmentation of large real-world objects (e.g. agricultural fields, buildings) as well as delineating small objects (e.g. swimming pools, single trees). VHR image in false-colour infrared (NIR / G ( B), showing vegetation in red, buildings and roads in light to dark grey, and swimming pools in light blue. 


\section{$5 \quad$ Future steps for image classification}

The knowledge base is the source for extracting impervious surface areas from optical images. Thresholds of NDVI, NDWI etc. are determined for general classes of mineral and metallic materials (fully and partially impervious materials, natural rock material, cars and trucks), artificial hydrocarbons, bare soil, vegetation (trees, shrubs, grassland, meadows, crops), and water or shadow by interpreting the statistics of real-world objects using the spectral reflectivity in Pléiades imagery. If necessary, the knowledge base can be revised and thresholds adapted by transferring the methodology to other Pléiades imagery of similar characteristics. The TOA calibration of the data aims to allow transferability of the thresholds, but this will be evaluated in a follow-up study. In the first step, thresholds are fixed and then optionally fuzzified if this results in a better transferable classification. Optional improvements in image classification and classification stability can be achieved by integrating additional data and drawing conclusions based on spatial concepts:

- Distance to roads (categories of GIP data): determining the distance from classified mineral surface materials to roads in order to calculate the probability of impervious surfaces (distinguishing impervious surfaces from natural mineral material such as bedrock or rock debris)

- Distance to running water (rivers, streams): the probability of rock material close to running water is valuable to distinguish real-world objects of natural mineral material from impervious surfaces

- Building dataset and LiDAR-Raster nDSM (1 m spatial resolution): to overcome the spatial displacement of buildings in optical imagery due to the effects of satellite image acquisitions

- DSM and DTM LiDAR-Raster: calculating object and topographic shadows at the time of optical image acquisition and including rule-based algorithms for refinement of image-object classification.

To overcome the mono-temporal view of the VHR data, freely available Sentinel-2 optical imagery (European Copernicus programme) will be integrated in the future as additional evidence: temporal characteristics of real-world objects are addressable with big-data timeseries analyses. Sentinels $2 \mathrm{~A}$ and $2 \mathrm{~B}$ acquire images with $10 \mathrm{~m}$ GSD for RGB and NIR, as well as with $20 \mathrm{~m}$ in red edge and the SWIR spectral region with a revisit time of 5 days under the same viewing conditions; for some areas in Austria, the frequency is increased to intervals of $2 / 3$ days due to overlapping swathes of adjacent orbits. Thus, seasonal variations (phenological, snow coverage, change in water level, topographic and object shadows), temporal changes (mowing or harvesting events), permanent changes with long temporal effects (soil-sealing, clear cuts), as well as temporally stable conditions (e.g. no change of impervious surface areas), can be detected and integrated into VHR remote-sensing analysis. Temporal information derived from inter-seasonal time-series analysis will be used as thematic information and compared with the image objects and classification derived from VHR satellite imagery using sophisticated plausibility checks and validation. A connection to the Sentinel 2 Semantic Data Cube Austria (www.sen2cube.at; Tiede et al., 2019) is envisaged, where human-like queries on all Sentinel 2 data for Austria can be executed on semantically 
enriched Sentinel-2 data (Augustin et al., 2019); the results can be integrated as an additional evidence layer.

\section{Conclusion}

The conceptual object- and knowledge-based classification framework presented here for assessing impervious surface areas is the result of a preliminary study to increase the reproducibility, transferability and transparency of VHR remote-sensing based approaches. VHR satellite data is the only data source meeting the requirements for spatial analysis and planning, while data actuality and spatial coverage, as well as spatial and spectral resolution (sensor-calibrated data), are the highest priority for up-to-date and cost-effective information for large areas. Using knowledge- and rule-based classification systems (including known and adaptable thresholds and a-priori knowledge) aims to increase both the transparency and the transferability of the methodologies. However, parameterized image segmentation is still a challenging task and requires expert and/or user evaluations. Automation by iterative segmentation processes and expert evaluation is just one approach to address segmentation quality issues: in general, the over-segmentation of real-world objects in imagery and further object-refinement using additional knowledge are recommended. Focus on one sensor family (same resolution and bit depth) and sound calibration help to increase the degree of transferability. The integration of ancillary data with the help of spatial concepts in an objectbased data model is valuable, e.g. to correct spatial displacements of high real-world objects due to sensor-viewing effects, distinguishing water from topographic or object shadows, or increasing classification stability and validity by integrating a-priori knowledge with classification plausibility. Additionally, multi-temporal (big) data analyses are envisaged to incorporate knowledge on seasonal variability of geo-objects, or to identify finite changes in land cover or land use (e.g. soil-sealing). Detecting annual changes using VHR imagery in combination with indications from satellite data that are spatially coarser but of temporal high resolution requires sophisticated strategies over time, concentrating on relevant objects only. Thus, as an overall conclusion, remote-sensing monitoring approaches for land-cover or landuse classes (such as imperviousness) demand a modular, extendable and adaptable methodological design which can be improved with future developments and data.

\section{Acknowledgement}

This work was supported by the Provincial Government of Salzburg. 


\section{References}

Andrés, S., Arvor, D., Mougenot, I., Libourel, T., \& Durieux, L. (2017). Ontology-based classification of remote sensing images using spectral rules. Computers \& Geosciences, 102, 158-166. doi:10.1016/j.cageo.2017.02.018

Arvor, D., Belgiu, M., Falomir, Z., Mougenot, I., \& Durieux, L. (2019). Ontologies to interpret remote sensing images: why do we need them? GIScience \& Remote Sensing, 56(6), 911-939. doi:10.1080/15481603.2019.1587890

Augustin, H., Sudmanns, M., Tiede, D., Lang, S., \& Baraldi, A. (2019). Semantic Earth Observation Data Cubes. Data, 4(3), 102. doi:10.3390/data4030102

Baatz, M., \& Schäpe, A. (2000). Multiresolution Segmentation: an optimization approach for high quality multi-scale image segmentation. In J. Strobl, T. Blaschke, \& G. Griesebner (Eds.), Angewandte Geographische Informationsverarbeitung XII - Beiträge zum AGIT-Symposium Sal₹burg 2000 (pp. 12-23). Heidelberg: Wichmann.

Banko, G., Mansberger, R., Gallaun, H., Grillmayer, R., Prüller, R., Riedl, M., Stemberger, W., Steinnocher, K., Walli, A. (2014). Land use \& land cover mapping in Europe: Current practice, trends and future. Examples from national approaches: LISA-the Austrian approach. Annual Book Series „Remote Sensing and Digital Image Processing".'Land Use \& land cover mapping in Europe: Current practice, trends and future'. Springer-Verlag.

Blaschke, T., Hay, G. J., Kelly, M., Lang, S., Hofmann, P., Addink, E., Queiroz, F.R, van der Meer, F., van der Werff, H., van Coillie, F., Tiede, D. (2014). Geographic Object-Based Image Analysis Towards a new paradigm. Isprs Journal of Photogrammetry and Remote Sensing, 87(0), 180-191. doi:10.1016/j.isprsjprs.2013.09.014

Blaschke, T., \& Strobl, J. (2001). What's wrong with pixels? Some recent developments interfacing remote sensing and GIS. Zeitschrift für Geoinformationssysteme, 6, 12-17.

Chen, G., Hay, G. J., Carvalho, L. M. T., \& Wulder, M. A. (2012). Object-based change detection. International Journal of Remote Sensing, 33(14), 4434-4457. doi:10.1080/01431161.2011.648285

Drăguț, L., Csillik, O., Eisank, C., \& Tiede, D. (2014). Automated parameterisation for multi-scale image segmentation on multiple layers. Isprs Journal of Photogrammetry and Remote Sensing, 88(0), 119-127. doi:10.1016/j.isprsjprs.2013.11.018

Hamedianfar, A., Shafri, H. Z. M., Mansor, S., \& Ahmad, N. (2014). Improving detailed rule-based feature extraction of urban areas from WorldView-2 image and lidar data. International Journal of Remote Sensing, 35(5), 1876-1899. doi:10.1080/01431161.2013.879350

Heiden, U., Segl, K., Roessner, S., \& Kaufmann, H. (2007). Determination of robust spectral features for identification of urban surface materials in hyperspectral remote sensing data. Remote Sensing of Environment, 111(4), 537-552. doi:10.1016/j.rse.2007.04.008

Hossain, M. D., \& Chen, D. (2019). Segmentation for Object-Based Image Analysis (OBIA): A review of algorithms and challenges from remote sensing perspective. Isprs Journal of Photogrammetry and Remote Sensing, 150, 115-134. doi:10.1016/j.isprsjprs.2019.02.009

Kotthaus, S., Smith, T. E. L., Wooster, M. J., \& Grimmond, C. S. B. (2014). Derivation of an urban materials spectral library through emittance and reflectance spectroscopy. Isprs Journal of Photogrammetry and Remote Sensing, 94(0), 194-212. doi:10.1016/j.isprsjprs.2014.05.005

Lang, S. (2008). Object-based image analysis for remote sensing applications - modeling reality - dealing with complexity. In T. Blaschke, S. Lang, \& G. J. Hay (Eds.), Object-Based Image Analysis - Spatial Concepts for Knowledge-Driven Remote Sensing Applications (pp. 3-27). Berlin: Springer.

Matsuyama, T., \& Hwang, V.S.-S. (1990). SIGMA: A Knowledge-Based Aerial Image Understanding System. Plenum Press, New York and London. 
Myint, S. W., Gober, P., Brazel, A., Grossman-Clarke, S., \& Weng, Q. (2011). Per-pixel vs. object-based classification of urban land cover extraction using high spatial resolution imagery. Remote Sensing of Environment, 115(5), 1145-1161. doi:10.1016/j.rse.2010.12.017

Strahler, A. H., Woodcock, C. E., \& Smith, J. A. (1986). On the nature of models in remote sensing. Remote Sensing of Environment, 20(2), 121-139. doi:10.1016/0034-4257(86)90018-0

Strasser, T., Lang, S., Riedler, B., Pernkopf, L., \& Paccagnel, K. (2014). Multiscale Object Feature Library for Habitat Quality Monitoring in Riparian Forests. Geoscience and Remote Sensing Letters IEEE, 11(2), 559-563. doi:10.1109/LGRS.2013.2278335

Tiede, D., Lang, S., Albrecht, F., \& Hoelbling, D. (2010). Object-based class modeling for cadastreconstrained delineation of geo-objects. Photogrammetric Engineering and Remote Sensing, 76(2), 193-202. doi:10.14358/PERS.76.2.193

Tiede, D., Sudmanns, M., Augustin, H., Lang, S., \& Baraldi, A. (2019). Sentinel-2 Semantic Data \& Information Cube Austria'. In: Soille, P., Loekken, S., \& S. Albani (Eds.), Proceedings of 2019 Big Data from Space (BiDS'19) (pp. 65-68). Publications Office of the European Union.

Umweltbundesamt (2020). Flächeninanspruchnahme in Österreich im Durchschnitt der Drei-JahresPeriode 2017-2019. Retrieved from https://www.umweltbundesamt.at/umweltthemen/boden/flaecheninanspruchnahme

Weng, Q. (2012). Remote sensing of impervious surfaces in the urban areas: Requirements, methods, and trends. Remote Sensing of Environment, 117, 34-49. doi:10.1016/j.rse.2011.02.030 